Published in final edited form as:

Laryngoscope. 2014 March ; 124(3): E56-E63. doi:10.1002/lary.24326.

\title{
RGS21, A Regulator of Taste and Mucociliary Clearance?
}

\author{
Adam J. Kimple, MD, PhD \\ Department of Otolaryngology-Head and Neck Surgery, University of North Carolina at Chapel \\ Hill, North Carolina \\ Department of Pharmacology, University of North Carolina at Chapel Hill, North Carolina
}

\begin{abstract}
Alaina L. Garland, PhD
Cystic Fibrosis/Pulmonary Research and Treatment Center, University of North Carolina at Chapel Hill, North Carolina

Staci P. Cohen, PhD

Department of Pharmacology, University of North Carolina at Chapel Hill, North Carolina

\section{Vincent Setola, PhD}

Department of Pharmacology, University of North Carolina at Chapel Hill, North Carolina

Francis S. Willard, PhD

Department of Pharmacology, University of North Carolina at Chapel Hill, North Carolina
\end{abstract}

\author{
Thomas Zielinski, PhD \\ BellBrook Labs, Madison, Wisconsin, U.S.A
}

Robert G. Lowery, PhD

BellBrook Labs, Madison, Wisconsin, U.S.A

\section{Robert Tarran, PhD}

Department of Cell and Molecular Physiology, University of North Carolina at Chapel Hill, North Carolina

Cystic Fibrosis/Pulmonary Research and Treatment Center, University of North Carolina at Chapel Hill, North Carolina

\section{David P. Siderovski, PhD}

Department of Pharmacology, University of North Carolina at Chapel Hill, North Carolina

\begin{abstract}
Objectives/Hypothesis: Motile cilia of airway epithelial cells help to expel harmful inhaled material. Activation of bitterant-responsive G protein-coupled receptors (GPCRs) is believed to potentiate cilia beat frequency and mucociliary clearance. In this study, we investigated whether regulator of G protein signaling-21 (RGS21) has the potential to modulate signaling pathways connected to airway mucociliary clearance, given that RGS proteins modulate GPCR signaling by acting as GTPase-accelerating proteins (GAPs) for the $\mathrm{G} a$ subunits of heterotrimeric G proteins.
\end{abstract}

\footnotetext{
(C) 2013 The American Laryngological, Rhinological and Otological Society, Inc

Send correspondence to Adam J. Kimple, MD, PhD, Department of Otolaryngology-Head and Neck Surgery, University of North Carolina Memorial Hospitals, 170 Manning Dr., Ground Floor Physician Office Building, CB 7070, Chapel Hill, NC 27599.

kimplead@med.unc.edu..

Level of Evidence: N/A.

The authors have no other funding, financial relationships, or conflicts of interest to disclose.

Footnote: After the submission of this abstract on October 6, 2012, an additional article on RGS21 has been published. ${ }^{49}$
} 
Study Design: This is a pilot investigation to determine if RGS21, a potential tastant specific RGS gene, is expressed in sinonasal mucosa, and to determine its specific $\mathrm{G} a$ substrate using in vitro biochemical assays with purified proteins.

Methods: Rgs21 expression in sinonasal mucosa was determined using quantitative, real-time PCR and a transgenic mouse expressing RFP from the Rgs21 promoter. Rgs 21 was cloned, overexpressed, and purified using multistep protein chromatography. Biochemical and biophysical assays were used to determine if RGS21 could bind and accelerate the hydrolysis of GTP on heterotrimeric $\mathrm{G} a$ subunits.

Results: Rgs21 was expressed in sinonasal mucosa and lingual epithelium. Purified recombinant protein directly bound and accelerated GTP hydrolysis on Ga subunits.

Conclusions: Rgs 21 is expressed in sinonasal mucosa, is amenable to purification as a recombinant protein, and can bind to $\mathrm{G} a_{\mathrm{i} / \mathrm{o} / \mathrm{q}}$ subunits. Furthermore, RGS21 can accelerate the hydrolysis rate of GTP on $\mathrm{G} a_{\mathrm{i}}$ subunits. This provides evidence that RGS21 may be a negative regulator of bitterant responses. Future studies will be needed to determine the physiological role of this protein in mucociliary clearance.

\section{Keywords}

Regulators of G protein signaling (RGS); G proteins; gustation

\section{INTRODUCTION}

Signal transduction through G protein-coupled receptors (GPCRs) and their associated heterotrimeric guanine nucleotide-binding proteins controls a wide variety of cellular activities, ranging from transmembrane ion flux to regulation of gene transcription. ${ }^{1,2}$ In addition to being the most frequent target of currently prescribed pharmaceuticals, ${ }^{3}$ GPCRs allow us to see, smell, and taste the world in which we live.

Mammalian taste can be divided into five components: bitter, sweet, umami (Japanese for "savory"), salty, and sour. ${ }^{4}$ Three of these tastes: bitter, sweet, and umami, are directly mediated through GPCRs. ${ }^{5-7}$ Upon the binding of a bitterant, sweetener, or umami-flavored compound to a tastant-responsive GPCR, the receptor acts as a guanine nucleotide exchange factor (GEF), promoting the release of guanine diphosphate (GDP) by the heterotrimeric Ga subunit. Upon the binding of an agonist, the GPCR acts as a guanine nucleotide exchange factor (GEF), promoting release of GDP by the heterotrimeric $\mathrm{G} \alpha$ subunit. This results in subsequent $\mathrm{G} a$-GTP binding and activation of downstream signal transduction pathways. ${ }^{5,8,9}$ Based on animal models, the Ga subunits that inhibit cAMP production $\left(\mathrm{G} a_{\mathrm{i} / \mathrm{o}}\right)$, specifically gustducin and transducin, are the primary mediators of taste signaling. ${ }^{10-12}$ In GPCR-initiated signaling cascades, the duration of activation is controlled by the rate of GTP hydrolysis by the Ga subunit.

Regulators of G protein signaling (RGS proteins) serve as GTPase-accelerating proteins (GAPs) for heterotrimeric G proteins, ${ }^{13,14}$ and can increase $\mathrm{G} \alpha$ GTP hydrolysis rates as much as 100-fold, with significant effects on signal kinetics ${ }^{15}$ or agonist detection thresholds. ${ }^{16}$

Taste (or "gustation") may seem like a relative luxury compared to the other senses. However, the sense of taste is thought to have evolved to allow organisms to distinguish between nourishing foods and poisonous toxins as well as sense alimentary sugar concentrations to modulate glucose uptake. ${ }^{17}$ Additionally, GPCR-mediated taste signaling, 
specifically bitter signaling, plays a role in modulating mucociliary clearance in respiratory mucosa. ${ }^{18,19}$

Mucociliary clearance (MCC) actively propels debris-laden mucus over a ciliated epithelial monolayer to the oropharynx where it is either expelled or swallowed. This process is particularly important in maintaining the paranasal sinuses where clearance is not augmented with cough or sneeze reflexes. ${ }^{20}$ The physiological importance of MCC is highlighted by the patient with cystic fibrosis (CF) or primary ciliary dyskinesia (PCD) where the airway surface layer (ASL) and ciliated epithelium, respectively, are compromised by genetic mutations. ${ }^{21}$ In addition to the pulmonary pathology associated with CF and PCD, the disruption of the MCC results in nearly universal sinusitis. ${ }^{22,23}$

Activating purinergic and bitter GPCR pathways on respiratory epithelium has been demonstrated to potentiate MCC. ${ }^{18,24-26}$ The discovery of a negative regulator of GPCR signaling that is selectively expressed in tastant responsive cells and respiratory epithelium would provide an additional target for pharmacologically augmenting MCC for acute or chronic infections or genetic diseases such as CF or PCD.

Von Bucholtz et al. proposed that RGS21 may be a potential GAP for taste receptor signaling based on their observation of taste cell-specific expression of Rgs 21 transcripts. ${ }^{27}$ While the expression pattern of Rgs 21 is in dispute, ${ }^{27,28}$ we hypothesized that Rgs 21 would be expressed in nonlingual areas that are known to contain taste receptors. In this report, we describe a novel anatomical location that expresses Rgs 21 and furthermore characterize the in vitro biochemical properties of this protein.

\section{MATERIALS AND METHODS}

\section{Chemicals and Assay Materials}

Unless otherwise noted, all chemicals were the highest grade available from Sigma Aldrich (St. Louis, MO) or Fisher Scientific (Pittsburgh, PA).

\section{Production of RGS21::RFP BAC Transgenic Mice}

A bacterial artificial chromosome (BAC) from mouse chromosome 1 (RP23-126D12: nucleotides $146,254,848$ to $146,486,740$ ) was engineered by the University of North Carolina Neuroscience Center BAC Engineering Core Facility ${ }^{29,30}$ so that the RGS21 promoter drove expression of Tag-Red Fluorescent Protein (TagRFP). Pronuclear injections were performed and $\mathrm{C} 57 \mathrm{~B} 1 / 6 \mathrm{XDBA} 2$ hybrid embryos were implanted into pseudo-pregnant females by the UNC Animal Models Core. Gene expression was confirmed and RGS21::RFP BAC-transgenic founder mice were crossed with C57Bl/6J wildtype mice. All animal protocols were approved by the Institutional Animal Care and Use Committee (IACUC) of the University of North Carolina and all animals were cared for in an Association for Assessment and Accreditation of Laboratory Animal Care (AAALAC)accredited vivarium according to NIH standards.

\section{Cloning}

The human RGS21 open-reading frame was cloned using the sense primer $5^{\prime}$ -

TACTTCCAATCCAATGCGATGCCAGTGAAATGCTG-3' and antisense primer 5'TTATCCACTTCCAATGCGTTATCACAAAAAAGGGAG- $3^{\prime}$ with an annealing temperature of $56^{\circ} \mathrm{C}$ and an extension time of 20 seconds with Phusion thermostable DNA polymerase (New England Biolabs). Following amplification, a 498 bp band was resolved using agarose electrophoresis and subsequently cloned into a ligation-independent cloning vector to make a tobacco etch virus protease (TEV)-cleavable $\mathrm{His}_{6}$-fusion protein $\left(\mathrm{His}_{6^{-}}\right.$ 
RGS21) for production in Escherichia coli. ${ }^{31,32}$ QuickChange site-directed mutagenesis (Stratagene) was used to mutate Arg-126 of the RGS21 open reading frame to a glutamic acid residue with the sense primer: $5^{\prime}-$

GTCTCATGGCCAAGGATTCTTTCCCTGAGTTTCTGAAGTCAGAGATTTATAAAAA $-3^{\prime}$ and the antisense primer $5^{\prime}$ -

TTTTTATAAATCTCTGACTTCAGAAACTCAGGGAAAGAATCCTTGGCCATGAGA C- $3^{\prime}$.

\section{Protein Expression}

The vector encoding the His $_{6}$-RGS21 or -RGS21(R126E) was transformed into Escherichia coli BL21(DE3) cells (Novagen) and induced by the addition of $0.75 \mathrm{mM}$ isopropyl- $\beta$-Dthiogalactopyranoside. After overnight incubation at $20^{\circ} \mathrm{C}$, cells were pelleted by centrifugation. Cells were lysed using high-pressure homogenization with an EmulsiFlex (Avestin) and RGS21 was purified from the soluble fraction using a nickel-nitrilotriacetic acid (NTA) resin fast protein liquid chromatography (FPLC) column (FF HisTrap; GE Healthcare). His $_{6}$-RGS21 protein was cleaved with TEV protease and subsequent resolution of soluble protein on a calibrated 150-ml size exclusion column (Sephacryl S200, GE Healthcare) in S200 buffer (50 mM Tris pH 7.5, $150 \mathrm{mM} \mathrm{NaCl}, 5 \%$ (w/v) glycerol). Protein was concentrated to $1 \mathrm{mM}$, as determined by A280 nm measurements upon denaturation in guanidine hydrochloride.

\section{Tissue Expression}

Human sinonasal ribonucleic acid (RNA) was a gift from Dr. Adam Zanation and Dr. Charles Ebert. Human circumvallate papillae tissue was a gift from Dr. Marion Couch. Both samples were obtained using an Institutional Review Board-approved protocol after informed consent was obtained by study participants.

Total RNA isolated from human liver was purchased from Clonetech (Mountain View, CA). Quantitative, real-time reverse transcription-polymerase chain reaction (qRT-PCR) experiments were performed in triplicate on RNA isolated from the indicated tissues exactly as described using gene-specific primers and 6-carboxyfluorescein (FAM) and 6carboxytetramethylrhodamine (TAMRA) dual-labeled probes. ${ }^{33}$ Primer sequences: Human Rgs21: forward, 5'-TGC-TGT-TTC-TAC-AGG-TCA-CC-3'; reverse 5'-GTT-GGC-TAAAAG-CGT-GTC-CA-3'; probe, 5'-FAM-CTG-CGG-AAA-CAA-TGA-CAT-GGT-CTGTAMRA-3'; human 18S: forward 5'-AGA AAC GGC TAC CAC ATC CA-3'; reverse, 5'CTC GAA AGA GTC CTG TAT TGT-3'; Probe 5'-FAM-AG GCA GCA GGC GCG CAA ATT ACQ-TAMRA- $3^{\prime}$. The number of cycles until threshold $(\mathrm{Ct})$ was determined using an ABI Prism 7700 Sequence Detector System (Applied Biosystems, Carlsbad, CA) using triplicate (or greater) determinations. To normalize for the efficiency of mRNA extraction, the $C_{t}$ value of $18 \mathrm{~S}$ was subtracted from the $C_{t}$ of $\operatorname{Rgs} 21$ using the $\Delta \Delta C_{t}$ normalization as previously described. ${ }^{34}$

\section{Circumvallate Expression}

Tongues were removed from RGS21::RFP mice and wild-type littermates after transcardial perfusion with $0.9 \%$ saline followed by $4 \%$ paraformaldehyde in PBS (Pierce). After postfixation in 4\% PFA followed by cryopreservation in 30\% sucrose, tongues were frozen and sectioned on a Leica cryostat (-18 degrees C, 12-micron sections). Slices containing the circumvallate papillae were mounted onto chilled FisherBrand Super-Frost Plus glass slides and stored at $-80^{\circ} \mathrm{C}$ until assay. For immunolabeling of Tag-RFP, sample-containing slides were first permeabilized in $0.1 \%$ Triton X-100 in PBS (PBS-T) on ice for 20 minutes, then incubated in $2 \%(\mathrm{v} / \mathrm{v})$ goat serum in PBS-T (blocking buffer) for 1 hour to block nonspecific protein binding sites. Samples were then incubated in blocking buffer containing a 1:500 
dilution of Evrogen rabbit anti-mouse-tRFP antibody (reconstituted exactly as recommended by the manufacturer) for 1 hour at room temperature, then overnight at 4 degrees with gentle orbital rotation. The next day, sample-containing slides were washed three times with PBS$\mathrm{T}$, then blocked for 30 minutes in blocking buffer and incubated for 1 hour with Alexa 488conjugated goat anti-rabbit IgG secondary antibody (Invitrogen) diluted 1:200 in blocking buffer. Afterward, samples were washed three times with PBS-T, washed once with sterile distilled water, and coverslipped with Vector (Burlingame, CA) fluorescence mounting medium containing DAPI. Confocal images were obtained using a Olympus Fluoview confocal microscope. Images were processed using ImageJ software (NIH, Bethesda, MD).

\section{Sinus Epithelial Cultures}

Mouse sinonasal epithelia (MSE) were obtained from RGS21::RFP transgenic mice and aged-matched, wildtype $\mathrm{C} 57 \mathrm{Bl} / 6 \mathrm{~J}$ mice by blunt dissection and then digested with protease XIV (1\%) and DNase (1\%) overnight at $4^{\circ} \mathrm{C}$ under a protocol approved by the UNC IACUC. ${ }^{35}$ The enzymatic reaction was stopped by washing cells in fetal bovine serumcontaining medium three times. The cells were then plated on Primaria tissue culture plates (BD Biosciences, San Jose, CA) for 3 hours to adhere the fibroblasts. Nonadherent cells were drawn off and plated on T-clear inserts (Corning-Costar, Tewksbury, MA) at 250,000 cells/well. Subsequent MSE were maintained in modified bronchial epithelial growth medium with $5 \% \mathrm{CO}_{2}$ at $37^{\circ} \mathrm{C}$ to create an air-liquid interface. The airway liquid surface was labeled with 10-kDa FITC/dextran $(0.2 \mathrm{mg} / \mathrm{ml}$; Sigma) prior to imaging with XZ confocal and bright field microscopy, as previously described. ${ }^{36}$

\section{Coprecipitation}

COS7 cells were plated in 6-well dishes and transfected with $1.5 \mathrm{ng}$ of KT3-G $a$ DNA at $70 \%$ confluency with Fugene 6 (Roche, Indianapolis, IN). After 48 hours, cells were lysed in buffer containing $20 \mathrm{mM}$ Tris (pH 7.5), $100 \mathrm{mM} \mathrm{NaCl}, 1 \mathrm{mM}$ EGTA, $1 \%$ Triton-100, and either $100 \mu \mathrm{M}$ GDP or $100 \mu \mathrm{M}$ GDP, $20 \mathrm{mM} \mathrm{NaF}$ and $30 \mu \mathrm{M} \mathrm{AlCl} 3$ to mimic the GTP hydrolysis transition state. Following lysis, insoluble components were separated by centrifugation at $14,000 \times \mathrm{g}$ at $4^{\circ} \mathrm{C}$ for 10 minutes. His $_{6}-\mathrm{RGS} 21$ protein $(10 \mu \mathrm{g})$ was then added to the clarified cell lysate and rocked at $4^{\circ} \mathrm{C}$ for 1 hour before the addition of NTAagarose and continued incubation overnight at $4^{\circ} \mathrm{C}$. NTA-agarose was then washed four times with lysis buffer, and bound proteins were eluted with loading buffer and subjected to SDS-PAGE electrophoresis, followed by transfer to nitrocellulose and detection by KT3antibody and chemiluminescence.

\section{Surface Plasmon Resonance (SPR)}

Wildtype $\mathrm{His}_{6}-\mathrm{G} a_{\mathrm{i} 1}$ protein was immobilized onto NTA sensor chip (GE Healthcare, Sweden) exactly as previously described. ${ }^{37}$ Affinities of RGS21 proteins to immobilized $\mathrm{G} a_{\mathrm{i} 1}$ were calculated using equilibrium saturation binding analyses using Prism v. 5.0b (GraphPad Software, La Jolla, CA).

\section{Transcreener GDP Assay}

The $\mathrm{G} \alpha_{\mathrm{i} 1}(\mathrm{R} 178 \mathrm{M} / \mathrm{A} 326 \mathrm{~S})$ was purified as previously described. ${ }^{38}$ Transcreener GDP assays were conducted at $30^{\circ} \mathrm{C}$ on a Safire ${ }^{2}$ (Tecan) multi-well reader in 384-well black roundbottom plates (Corning, Tewksbury, MA). Fluorescence polarization was read using an excitation and emission of 635-nm excitation and 670-nm respectively. Photomultiplier tubes were adjusted so that a free tracer reference was $20 \mathrm{mP}$. All experiments were conducted in $20 \mathrm{mM}$ Tris (pH 7.5), $1 \mathrm{mM}$ EDTA, $10 \mathrm{mM} \mathrm{MgCl}_{2}, 10 \mu \mathrm{M}$ GTP, $8 \mu \mathrm{g} / \mathrm{mL}$ GDP antibody, and $2 \mathrm{nM}$ tracer. RGS GAP activity was determined by measuring by the change in polarization $(\Delta \mathrm{mP})$ caused by the addition of RGS protein to $\mathrm{G} a_{\mathrm{i} 1}$ relative to $\mathrm{G} a_{\mathrm{i} 1}$ 
alone. The steady state "GAP factor" was defined as the ratio between the GTPase rate in the presence and absence of RGS protein.

\section{${ }^{32}$ P-GTP Hydrolysis Assays}

The intrinsic and RGS-stimulated GTP hydrolysis rate ${ }^{32}$ of $\mathrm{G} a_{\mathrm{i} 1}$ subunits was assessed by monitoring the production of radioactive phosphate from $\left[\gamma^{32} \mathrm{P}\right]-\mathrm{GTP}$ during a single round of GTP hydrolysis exactly as previously described. ${ }^{39}$

\section{RESULTS}

RGS21 contains a single isolated RGS domain composed of the canonical $9 a$ helices. ${ }^{40} \mathrm{~A}$ sequence alignment of various human RGS domains, produced by ClustalX, ${ }^{41}$ demonstrates RGS21 is most similar to RGS2. The amino acid sequence of the RGS domain of RGS21 and RGS2 are 64\% identical and 79\% similar (Fig. 1). Based on comparison to RGS12, ${ }^{42}$ mutation of Arg-126 in RGS21 was predicted to produce an RGS21 protein mutant that would be properly folded but inactive with respect to Ga subunit binding and GAP activity (Fig. 1; star).

To detect if $\operatorname{Rgs} 21$ is transcribed in sinonasal mucosa, qRT-PCR of RNA isolated from the circumvallate (C.V.) papillae, liver and sinus mucosa was conducted (Fig. 2A). Expression was normalized to C.V. expression and the $18 \mathrm{~S}$ housekeeping transcript using the $\Delta \Delta C_{t}$ method. ${ }^{34}$ Sinonasal mucosa demonstrated a high expression level of $R g s 21,428 \%$ of the level detected in the $\mathrm{CV}$ papillae. In contrast, RNA isolated from the liver demonstrated $\approx 5 \%$ of the expression of the CV papillae. At 40 cycles of amplification, Rgs 21 was undetectable in two of the three liver RNA samples and at only a trace level in the third. To provide additional evidence that RGS21 is expressed in sinonasal mucosa, a BAC transgenic mouse strain was generated that expressed RFP from the RGS21 promoter. In circumvallate papillae (Fig. 2B, C) and ex vivo sinonasal cultures (Fig. 2D, E, and F), RFP expression was observed in the RGS21::RFP transgenic mice but not in wildtype mice.

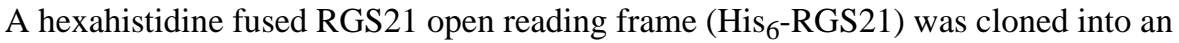
eukaryotic expression vector, over-expressed in Escherichia coli, and purified using affinity chromatography. His 6 -RGS21, with an expected molecular weight of 20,278 Da, was eluted with $30 \%$ imidazole (Fig. 3. "NTA"). TEV protease was used to cleave the affinity tag, resulting in a protein with a molecular weight of $17,856 \mathrm{Da}$ (Fig. 3. "Cleaved") prior to resolution on a calibrated $150 \mathrm{ml}$ size exclusion column (Fig. 3. "Gel Filtration Fraction"). Fractions 23-28 were pooled and concentrated for subsequent assays.

We determined the G $\alpha$-selectivity of RGS21 using pulldown assays with various, epitopetag labeled $\mathrm{G} a$ subunits (KT3-G $a$ ) expressed in mammalian cells (Fig. 4). His 6 -RGS21 protein was observed to bind $\mathrm{KT} 3-\mathrm{G} a_{\mathrm{i} 1},-\mathrm{G} a_{\mathrm{i} 2},-\mathrm{G} a_{\mathrm{i} 3},-\mathrm{G} a_{\mathrm{o}},-\mathrm{G} a_{\mathrm{q}}$ in their transition state form (e.g., ligated with GDP, $\mathrm{AlF}_{4}^{-}$, and $\mathrm{Mg}^{2+}$ [AMF]). No significant binding was observed to any $\mathrm{G} a$ in the GDP state, and $\mathrm{G} a_{\mathrm{s}}$ was not found to interact with $\mathrm{His}_{6}-\mathrm{RGS} 21$ in any state.

$\mathrm{His}_{6}-\mathrm{G} a_{\mathrm{i} 1}$ was covalently linked to a sensor surface for quantification of RGS21 binding affinity using SPR. Purified RGS21/G $a_{\mathrm{i} 1}$ (AMF) bound in a dose dependent manner (Fig. $5 \mathrm{~A}$ ); however, no significant binding was observed to $\mathrm{G} \alpha_{\mathrm{i}}$ (GDP) (Fig. 5B, open triangle). Equilibrium binding analysis demonstrated an affinity between RGS21 and $\mathrm{G} a_{\mathrm{i} 1}$ of $57.0 \mathrm{nM}$ (95\% CI $28.3-85.7 \mathrm{nM}$ ). No binding was observed to the RGS21(R126E) point mutant (Fig. 3B, diamond). 
To determine if RGS21 can accelerate hydrolysis of GTP on G $a_{\mathrm{i} 1}$, the production of GDP from GTP was monitored using the Transcreener GDP assay. The addition of RGS21 to $\mathrm{G} a_{\mathrm{i} 1}$ resulted in an increased change in polarization compared to buffer alone or RGS21(R126E) (Fig. 6A). Conversion of fluorescence polarization to GDP production demonstrated that RGS21 hydrolyzed GTP with a $k_{\text {cat }}$ of $0.13 \mathrm{~min}^{-1}(95 \%$ C.I $0.12-0.14$ $\mathrm{min}^{-1}$ ) compared to RGS21(R126E) or buffer alone which hydrolyzed GTP at a rate of $0.011 \mathrm{~min}^{-1}$ (95\% C.I $0.010-0.012 \mathrm{~min}^{-1}$ ) and 0.015 (95\% C.I. $0.014-0.016 \mathrm{~min}^{-1}$ ), respectively (Fig. 6B). Based on these steady-state GTPase rates, RGS21 has a GAP factor of 8.79 with $\mathrm{G} a_{\mathrm{i} 1}$, while RGS21(R126E) and buffer had GAP factors of 0.75 and 1.00 respectively.

To confirm the results of the Transcreener GDP assay, a single round of GTP hydrolysis was measured for $\mathrm{G} a_{\mathrm{i} 1}$ preloaded with $\left[\gamma^{32} \mathrm{P}\right]-\mathrm{GTP}$ (Fig. 6D). The intrinsic hydrolysis rate of $\mathrm{G} a_{\mathrm{i} 1}$ was $0.0070 \mathrm{~min}^{-1}\left(95 \% \mathrm{CI} 0.0057-0.0083 \mathrm{~min}^{-1}\right)$ while the addition of RGS21 increased the rate to $0.13 \mathrm{~min}^{-1}\left(\left(95 \% \mathrm{CI} 0.08-0.17 \mathrm{~min}^{-1}\right)\right.$.

\section{DISCUSSION}

RGS proteins have been identified in plants, yeast, fungi, protozoa and animals. ${ }^{14,43-46}$ As signaling complexity in organisms increases, additional RGS proteins are typically identified, with humans having 37 RGS proteins and unicellular organism typically having one or two RGS proteins. In general, orthologs of RGS21 can be identified in mammals (Supplemental Data). Based on sequence similarity, RGS proteins are broken down into 10 different families. ${ }^{14}$ Based on homology to other RGS domains as well as the absence of additional protein-protein interactionldomains, RGS21 is a member of the R4 family, most closely related by sequence to RGS2 (Fig. 1). Unlike R9 or R12 family members, R4 RGS domains, including RGS21, contain an isolated RGS domain consisting of a 9-helical bundle (Fig. 1). While other RGS proteins utilize additional domains or membrane targeting sequences to provide receptor specificity and localization, these features appear absent in RGS21. It is possible that the receptor specificity for RGS21 is engendered by the selective expression observed by Bucholtz et al. ${ }^{27}$ and supported by our results.

Because of recent evidence implicating bitter receptors in modulating mucociliary clearance ${ }^{18,19}$ and the described expression of RGS21 in tastant responsive cells, ${ }^{27}$ we used qRT-PCR to evaluate Rgs 21 transcription in RNA isolated from RNA isolated from human sinus mucosa. Rgs 21 was expressed in the C.V. papillae and not in the liver, consistent with previous work. ${ }^{27}$ Additionally, Rgs 21 was transcribed to a high level in human sinonasal mucosa (Fig. 2A). Because antibodies do not presently exist for RGS21, we sought an alternative method to validate that $R g s 21$ is expressed in sinonasal mucosa. To this end, RFP driven by the RGS21 promoter was observed in ex vivo cultures of mouse sinonasal epithelium. These results are consistent with the hypothesis that RGS21 is a negative regulator of gustation and is expressed in sinonasal mucosa.

While RGS proteins interact with a variety of $\mathrm{G} a$ subunits, $\mathrm{R} 4$ family members classically interact with $\mathrm{G} a_{\mathrm{i} / \mathrm{o}}$ and $\mathrm{G} a_{\mathrm{q}}$ in a nucleotide-dependent manner; however, RGS2, which is most similar to RGS21, binds exclusively to $\mathrm{G} a_{\mathrm{q}} \cdot{ }^{40}$ To assess the $\mathrm{G} a$ binding partners of RGS21, we produced recombinant RGS21 in Escherichia coli and then used chromatography to purify monodispersed proteins (Fig. 3). Using this highly purified recombinant protein and mammalian cell lysates over-expressing epitope tagged $\mathrm{G} a_{\mathrm{i} 1}, \mathrm{G} a_{\mathrm{i} 2}$, $\mathrm{G} a_{\mathrm{i} 3}, \mathrm{G} a_{\mathrm{o}}, \mathrm{G} a_{\mathrm{q}}$, and $\mathrm{G} a_{\mathrm{s}}$ coprecipitation experiments were performed (Fig. 4). These studies indicate that RGS21 interacts with $\mathrm{G} a_{\mathrm{i} 1}, \mathrm{G} a_{\mathrm{i} 2}, \mathrm{G} a_{\mathrm{i} 3}, \mathrm{G} a_{\mathrm{o}}$, and $\mathrm{G} a_{\mathrm{q}}$ in a nucleotidedependent manner, specifically in their transition state mimetic form (AMF). However RGS21 did not bind any GDP-bound $\mathrm{G} a_{\mathrm{i}}$ proteins or $\mathrm{G} a_{\mathrm{s}}$ in either state. While RGS21 is 
most similar to RGS2 based on sequence similarity, this binding pattern is more consistent with other members of the R4 family which typically bind to both $\mathrm{G} a_{\mathrm{i} / \mathrm{o}}$ and $\mathrm{G} a_{\mathrm{q}} \cdot{ }^{40}$

While the pull-down assays provide data regarding binding, they do not allow for the precise determination of binding affinities or exclude the possibility that other proteins present in the cellular lystates are involved in the interaction. Typically RGS/G $a$ interactions have affinity constants of $\approx 10 \mathrm{nM}$ to $100 \mathrm{nM}$; however, some atypical RGS/G $a$ pairs have affinities as low as $\approx 1 \mu \mathrm{M} .{ }^{47}$ Using SPR, the $K_{D}$ was determined to be $57.0 \mathrm{nM}$ (95\% CI 28.3-85.7 nM) (Fig. 5), consistent with other RGS/G $a$ affinities, and no significant binding was seen between RGS21 and $\mathrm{G} a_{\mathrm{i} 1}(\mathrm{GDP})$ or between RGS21(R126E) and $\mathrm{G} a_{\mathrm{i} 1}$ (AMF) at concentrations 100 -fold above the $K_{D}$.

While binding is often used as a surrogate for acceleration of GTP hydrolysis by RGS proteins ${ }^{48}$ the hallmark of the RGS/G $\alpha$ interaction is the ability to accelerate GTP hydrolysis. To see if RGS21 is capable of accelerating the hydrolysis of GTP on Ga subunits, the production of GDP was measured using the Transcreener GDP assay (Figs. 6A, 6B, and 6C). RGS21 was found to robustly increase the rate of steady state GTP hydrolysis on $\mathrm{G} a_{\mathrm{i} 1}(\mathrm{R} 178 \mathrm{M} / \mathrm{A} 326 \mathrm{~S})$. In this steady state assay, RGS21 had a GAP factor of 8.79 compared to RGS21(R126E) or buffer alone, which did not affect the steady state hydrolysis rate (Fig. 6C).

Increased GDP production was detected upon addition of RGS21 using the Transcreener GDP assay; however, this assay depends on two-point mutations that alter the kinetics of $\mathrm{G} a_{\mathrm{i} 1}$. To assess if RGS21 could accelerate GTP hydrolysis on wildtype $\mathrm{G} a_{\mathrm{i} 1}$, single turnover assays were performed with $\left[\gamma-{ }^{32} \mathrm{P}\right]-\mathrm{GTP}$. Consistent with the results obtained using the Transcreener GDP assay, GTP hydrolysis was dramatically enhanced upon the addition of RGS21.

\section{CONCLUSION}

RGS proteins can dramatically alter the kinetics of GPCR signaling and activation of bitterresponsive GPCRs has been shown to modulate mucocilary clearance in the sinonasal tract. ${ }^{18,19}$ We have demonstrated that RGS21, a putative tastant-specific RGS protein, is expressed in the sinonasal mucosa and can bind $\mathrm{G} a_{\mathrm{i} / \mathrm{o} / \mathrm{q}}$ heterotrimeric $\mathrm{G}$ proteins. Specifically, RGS21 acts as a GAP for $\mathrm{G} a_{\mathrm{i}}$ subunits which mediate gustatory signaling. We have also identified a loss of function point mutation that will help facilitate future studies. While additional work is needed to understand the role of RGS21 in modulating gustatory signaling and mucociliary clearance, our work provides supporting evidence that RGS21 is expressed selectively in tastant responsive tissue, and specifically the sinonasal epithelium and may be a negative regulator of gustation.

\section{Acknowledgments}

This work was supported by the National Institutes of Health Grants R01 GM082892 (D.P.S.), R44 NS059082 (R.G.L), and R01 HL108927 (R.T.). Adam J. Kimple gratefully acknowledges prior support of the UNC MD/PhD program (T32 GM008719) and the National Institute of Mental Health (F30 MH074266). Staci P. Cohen kindly acknowledges support from a National Institutes of Health/NIDCD Ruth L. Kirschstein NRSA Fellowship F32 DC011670.

We would like to thank Noah Sciaky for help obtaining mouse circumvallate papillae digital micrographs and Brian Buckley for provision of tissue from the RGS21::RFP transgenic mouse. 


\section{BIBLIOGRAPHY}

1. Gilman AG. G proteins: transducers of receptor-generated signals. Annu Rev Biochem. 1987; 56:615-649. [PubMed: 3113327]

2. Offermanns S. G-proteins as transducers in transmembrane signalling. Prog Biophys Mol Biol. 2003; 83:101-130. [PubMed: 12865075]

3. Jacoby E, Bouhelal R, Gerspacher M, Seuwen K. The 7 TM G-protein-coupled receptor target family. Chem Med Chem. 2006; 1:761-782. [PubMed: 16902930]

4. Yarmolinsky DA, Zuker CS, Ryba NJ. Common sense about taste: from mammals to insects. Cell. 2009; 139:234-244. [PubMed: 19837029]

5. Chandrashekar J, Mueller KL, Hoon MA, et al. T2Rs function as bitter taste receptors. Cell. 2000; 100:703-711. [PubMed: 10761935]

6. Nelson G, Hoon MA, Chandrashekar J, Zhang Y, Ryba NJ, Zuker CS. Mammalian sweet taste receptors. Cell. 2001; 106:381-390. [PubMed: 11509186]

7. Zhao GQ, Zhang Y, Hoon MA, et al. The receptors for mammalian sweet and umami taste. Cell. 2003; 115:255-266. [PubMed: 14636554]

8. Sainz E, Cavenagh MM, Gutierrez J, Battey JF, Northup JK, Sullivan SL. Functional characterization of human bitter taste receptors. Biochem J. 2007; 403:537-543. [PubMed: 17253962]

9. Bourne HR. How receptors talk to trimeric G proteins. Curr Opin Cell Biol. 1997; 9:134-142. [PubMed: 9069253]

10. Wong GT, Gannon KS, Margolskee RF. Transduction of bitter and sweet taste by gustducin. Nature. 1996; 381:796-800. [PubMed: 8657284]

11. He W, Yasumatsu K, Varadarajan V, et al. Umami taste responses are mediated by alphatransducin and alpha-gustducin. J Neurosci. 2004; 24:7674-7680. [PubMed: 15342734]

12. Kusakabe Y, Yasuoka A, Asano-Miyoshi M, et al. Comprehensive study on G protein alphasubunits in taste bud cells, with special reference to the occurrence of Galphai2 as a major Galpha species. Chem Senses. 2000; 25:525-531. [PubMed: 11015324]

13. Siderovski DP, Hessel A, Chung S, Mak TW, Tyers M. A new family of regulators of G-proteincoupled receptors? Curr Biol. 1996; 6:211-212. [PubMed: 8673468]

14. Kimple AJ, Bosch DE, Giguere PM, Siderovski DP. Regulators of G-protein signaling and their Galpha substrates: promises and challenges in their use as drug discovery targets. Pharmacol Rev. 2011; 63:728-749. [PubMed: 21737532]

15. Chen CK, Burns ME, He W, Wensel TG, Baylor DA, Simon MI. Slowed recovery of rod photoresponse in mice lacking the GTPase accelerating protein RGS9-1. Nature. 2000; 403:557560. [PubMed: 10676965]

16. Ferkey DM, Hyde R, Haspel G, et al. C. elegans G protein regulator RGS-3 controls sensitivity to sensory stimuli. Neuron. 2007; 53:39-52. [PubMed: 17196529]

17. Yee KK, Sukumaran SK, Kotha R, Gilbertson TA, Margolskee RF. Glucose transporters and ATPgated $\mathrm{K}+(\mathrm{KATP})$ metabolic sensors are present in type 1 taste receptor 3 (T1r3)-expressing taste cells. Proc Natl Acad Sci USA. 2011; 108:5431-5436. [PubMed: 21383163]

18. Lee RJ, Xiong G, Kofonow JM, et al. T2R38 taste receptor polymorphisms underlie susceptibility to upper respiratory infection. J Clin Invest. 2012; 122:4145-4159. [PubMed: 23041624]

19. Shah AS, Ben-Shahar Y, Moninger TO, Kline JN, Welsh MJ. Motile cilia of human airway epithelia are chemosensory. Science. 2009; 325:1131-1134. [PubMed: 19628819]

20. Antunes MB, Cohen NA. Mucociliary clearance-a critical upper airway host defense mechanism and methods of assessment. Curr Opin Allergy Clin Immunol. 2007; 7:5-10. [PubMed: 17218804]

21. Randell SH, Boucher RC. Effective mucus clearance is essential for respiratory health. Am J Respir Cell Mol Biol. 2006; 35:20-28. [PubMed: 16528010]

22. Halvorson DJ. Cystic fibrosis: an update for the otolaryngologist. Otolaryngol Head Neck Surg. 1999; 120:502-506. [PubMed: 10187942]

23. Neely JG, Harrison GM, Jerger JF, Greenberg SD, Presberg H. The otolaryngologic aspects of cystic fibrosis. Trans Am Acad Ophthalmol Otolaryngol. 1972; 76:313-324. [PubMed: 4667649] 
24. Morse DM, Smullen JL, Davis CW. Differential effects of UTP, ATP, and adenosine on ciliary activity of human nasal epithelial cells. Am J Physiol Cell Physiol. 2001; 280:C1485-1497. [PubMed: 11350744]

25. Hua X, Naselsky WC, Bennett WD, Ledent C, Senior BA, Tilley SL. Adenosine increases nasal mucociliary clearance rate in mice through $\mathrm{A}(2 \mathrm{~A})$ and $\mathrm{A}(2 \mathrm{~B})$ adenosine receptors. Laryngoscope. 2013; 123:306-310. doi: 10.1002/lary.23586. Epub 2012. [PubMed: 22965898]

26. Lazarowski ER, Tarran R, Grubb BR, van Heusden CA, Okada S, Boucher RC. Nucleotide release provides a mechanism for airway surface liquid homeostasis. J Biol Chem. 2004; 279:3685536864. [PubMed: 15210701]

27. von Buchholtz L, Elischer A, Tareilus E, et al. RGS21 is a novel regulator of G protein signalling selectively expressed in subpopulations of taste bud cells. Eur J Neurosci. 2004; 19:1535-1544. [PubMed: 15066150]

28. Li X, Chen L, Ji C, et al. Isolation and expression pattern of RGS21 gene, a novel RGS member. Acta Biochim Pol. 2005; 52:943-946. [PubMed: 16302027]

29. Shaner NC, Lin MZ, McKeown MR, et al. Improving the photostability of bright monomeric orange and red fluorescent proteins. Nat Methods. 2008; 5:545-551. [PubMed: 18454154]

30. Hollenback SM, Lyman S, Cheng J. Recombineering-based procedure for creating BAC transgene constructs for animals and cell lines. Curr Protoc Mol Biol. 2011 chapter 23:unit 23.14. doi: 10.1002/0471142727. mb2314s95.

31. Stols L, Gu M, Dieckman L, Raffen R, Collart FR, Donnelly MI. A new vector for highthroughput, ligation-independent cloning encoding a tobacco etch virus protease cleavage site. Protein Expr Purif. 2002; 25:8-15. [PubMed: 12071693]

32. Kimple AJ, Willard FS, Giguere PM, Johnston CA, Mocanu V, Siderovski DP. The RGS protein inhibitor CCG-4986 is a covalent modifier of the RGS4 Galpha-interaction face. Biochim Biophys Acta. 2007; 1774:1213-1220. [PubMed: 17660054]

33. Kim HS, Lee G, John SW, Maeda N, Smithies O. Molecular phenotyping for analyzing subtle genetic effects in mice: application to an angiotensinogen gene titration. Proc Natl Acad Sci USA. 2002; 99:4602-4607. [PubMed: 11904385]

34. Livak KJ, Schmittgen TD. Analysis of relative gene expression data using real-time quantitative PCR and the 2(-Delta Delta C(T)) Method. Methods. 2001; 25:402-408. [PubMed: 11846609]

35. Mall MA, Button B, Johannesson B, et al. Airway surface liquid volume regulation determines different airway phenotypes in liddle compared with betaENaC-overexpressing mice. J Biol Chem. 2010; 285:26945-26955. [PubMed: 20566636]

36. Worthington EN, Tarran R. Methods for ASL measurements and mucus transport rates in cell cultures. Methods Mol Biol. 2011; 742:77-92. [PubMed: 21547727]

37. Kimple AJ, Muller RE, Siderovski DP, Willard FS. A capture coupling method for the covalent immobilization of hexahistidine tagged proteins for surface plasmon resonance. Methods Mol Biol. 2010; 627:91-100. [PubMed: 20217615]

38. Zielinski T, Kimple AJ, Hutsell SQ, Koeff MD, Siderovski DP, Lowery RG. Two Galpha(i1) ratemodifying mutations act in concert to allow receptor-independent, steady-state measurements of RGS protein activity. J Biomol Screen. 2009; 14:1195-1206. [PubMed: 19820068]

39. Kimple AJ, Soundararajan M, Hutsell SQ, et al. Structural determinants of G-protein alpha subunit selectivity by regulator of G-protein signaling 2 (RGS2). J Biol Chem. 2009; 284:19402-19411. [PubMed: 19478087]

40. Soundararajan M, Willard FS, Kimple AJ, et al. Structural diversity in the RGS domain and its interaction with heterotrimeric G protein alpha-subunits. Proc Natl Acad Sci USA. 2008; 105:6457-6462. [PubMed: 18434541]

41. Thompson JD, Gibson TJ, Plewniak F, Jeanmougin F, Higgins DG. The CLUSTAL_X windows interface: flexible strategies for multiple sequence alignment aided by quality analysis tools. Nucleic Acids Res. 1997; 25:4876-4882. [PubMed: 9396791]

42. Willard FS, Kimple AJ, Johnston CA, Siderovski DP. A direct fluorescence-based assay for RGS domain GTPase accelerating activity. Anal Biochem. 2005; 340:341-351. [PubMed: 15840508] 
43. Johnston CA, Willard MD, Kimple AJ, Siderovski DP, Willard FS. A sweet cycle for Arabidopsis G-proteins: Recent discoveries and controversies in plant G-protein signal transduction. Plant Signal Behav. 2008; 3:1067-1076. [PubMed: 19513240]

44. Bosch DE, Kimple AJ, Manning AJ, et al. Structural determinants of RGS-RhoGEF signaling critical to Entamoeba histolytica pathogenesis. Structure. 2013; 21:65-75. [PubMed: 23260656]

45. Dohlman HG, Song J, Apanovitch DM, DiBello PR, Gillen KM. Regulation of G protein signalling in yeast. Semin Cell Dev Biol. 1998; 9:135-141. [PubMed: 9599408]

46. Zhang H, Tang W, Liu K, et al. Eight RGS and RGS-like proteins orchestrate growth, differentiation, and pathogenicity of Magnaporthe oryzae. PLoS Pathog. 2011; 7:e1002450. [PubMed: 22241981]

47. Bosch DE, Kimple AJ, Muller RE, et al. Heterotrimeric G-protein signaling is critical to pathogenic processes in Entamoeba histolytica. PLoS Pathog. 2012; 8:e1003040. [PubMed: 23166501]

48. Tesmer JJ, Berman DM, Gilman AG, Sprang SR. Structure of RGS4 bound to AlF4 - activated G(i alpha1): stabilization of the transition state for GTP hydrolysis. Cell. 1997; 89:251-261. [PubMed: 9108480]

49. Cohen SP, Buckley BK, Kosloff M, et al. Regulator of G-protein signaling-21 (RGS21) is an inhibitor of bitter gustatory signaling found in lingual and airway epithelia. J Biol Chem. 2012; 287:41706-41719. [PubMed: 23095746] 


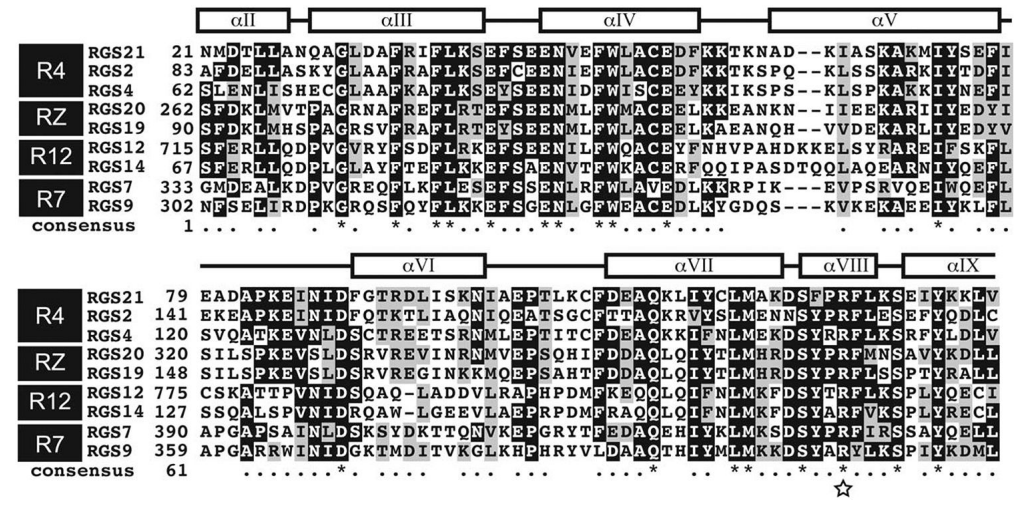

Fig. 1.

Multiple sequence alignment of the regulators of $\mathrm{G}$ protein signaling (RGS) domain of RGS21 and other RGS family members. Multiple sequence alignment (MSA) of the human RGS domains from RGS21, RGS2, RGS4, RGS20, RGS19, RGS12, RGS14, RGS7, and RGS9. RGS domains are frequently subdivided into nine subfamilies; highlighted in the MSA are members of the R4, R7, R12, and RZ families. The "consensus" amino acids are identified by Clustal $\mathrm{X}^{41}$ as either similar "*” or identical ".". The secondary structure is annotated above the MSA based on the crystal structure of RGS2 (PDB ID: 2V4Z). ${ }^{39}$ Mutation to arginine 129 of RGS21, highlighted by a star, is predicted to abolish binding to Ga subunits. 


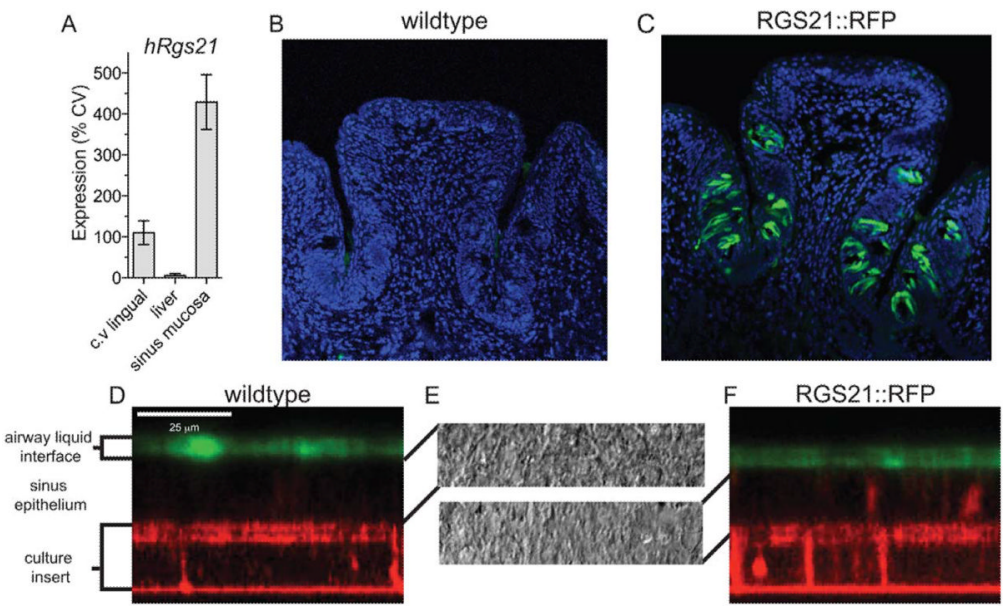

Fig. 2.

Regulator of G protein signaling-21 (RGS21) is expressed in sinus mucosa and circumvallate papillae. (A) Real-time, quantitative polymerase chain reaction (PCR) using fluorogenic probe detection was performed on total ribonucleic acid (RNA) from indicated human tissues. Variable quantities of RNA were normalized by comparison to $18 \mathrm{~S}$ ribosomal RNA and expression of RGS21 was set to $100 \%$ in the circumvallate (cv) papillae using established methods. ${ }^{34}$ Expression on RFP was detected in circumvallate papillae from (B) wildtype and (C) RGS21::RFP mice using anti-mouse-tRFP antibody and an Alexa 488-conjugated goat-anti-rabbit IgG secondary antibody. Nuclei are highlighted using 4',6diamidino-2-phenylindole (DAPI) staining. Sinonasal epithelium from wildtype (D) and RGS21::RFP transgenic (E) mice was cultured in an air-liquid interface and imaged for TagRFP protein expression (autofluorescence) by confocal microscopy. Air-liquid interface was highlighted by the addition of FITC-dextran to the airway surface liquid. (F) Bright field microscopy of wildtype (upper) and RGS21::RFP transgenic mice (lower) cultured epithelial cells. 


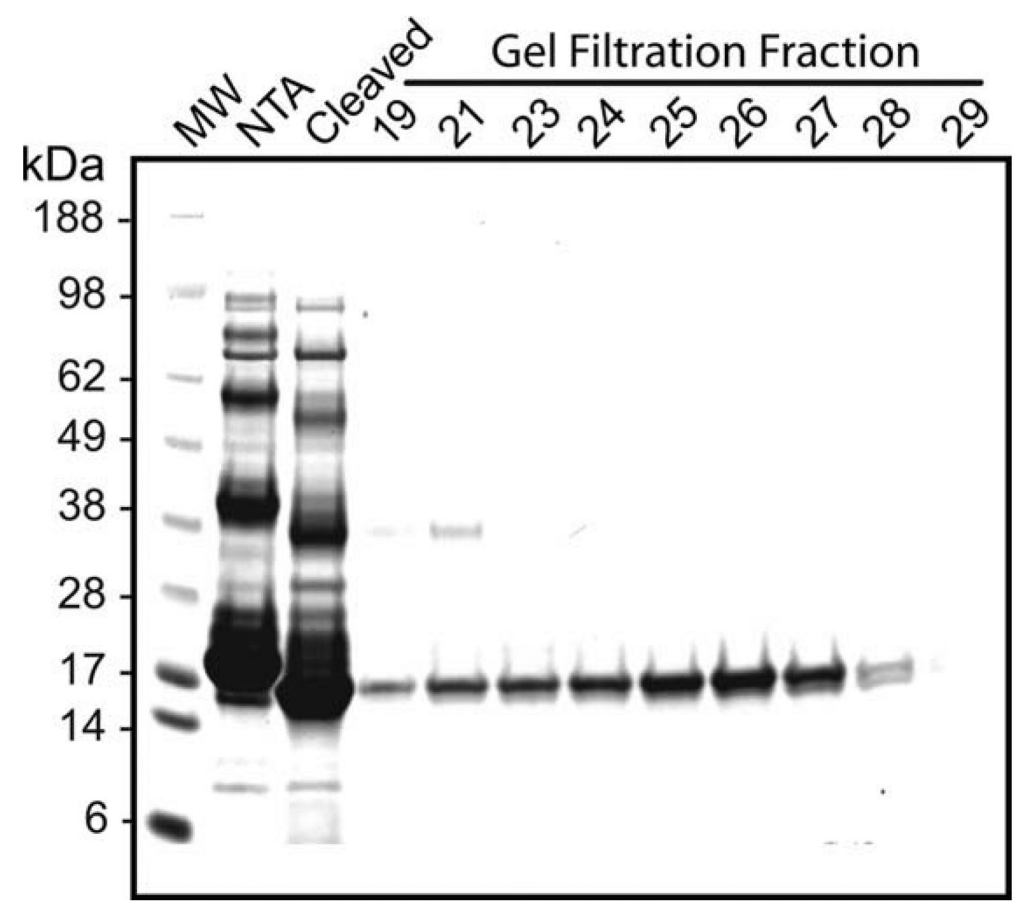

Fig. 3.

Recombinant regulator of G protein signaling-21 (RGS21) can be produced and purified from Escherichia coli. Aliquots after the initial affinity chromatography (NTA), after cleavage of the hexahistidine affinity tag with tobacco etch virus (TEV) protease (cleaved) and at indicted fractions during size exclusion chromatography (gel filtration fraction) were resolved using sodium dodecyl sulfate polyacrylamide gel electrophoresis (SDS-PAGE) and highlighted using Coomassie blue staining. 


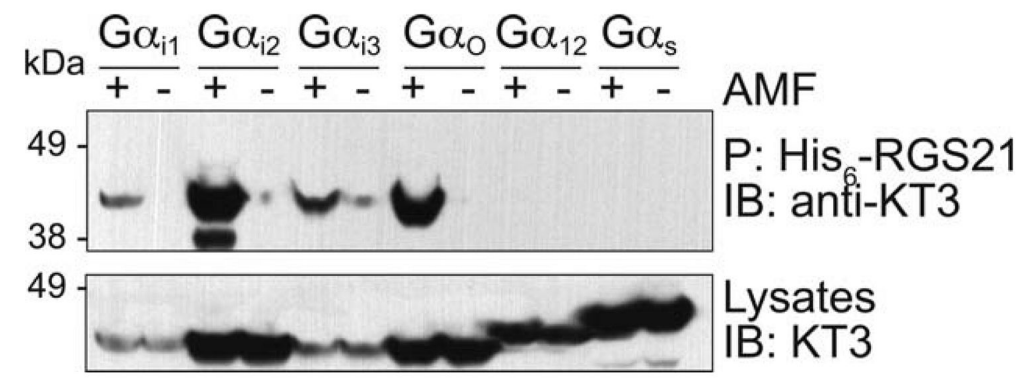

Fig. 4.

Recombinant regulator of G protein signaling-21 (RGS21) interacts with G $\alpha$ in a nucleotide dependent manner. COS7 cells were separately transfected with DNA encoding one of the indicated Ga subunits fused to the KT3 epitope. Cells were lysed in buffer containing GDP,

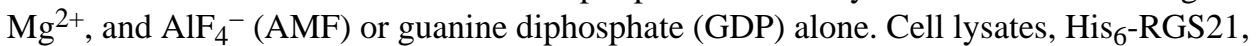
and NTA-agarose were incubated overnight prior to washing. Precipitated proteins were heat denatured prior to resolution by sodium dodecyl sulfate polyacrylamide gel electrophoresis (SDS-PAGE), transferred to a nitrocellulose membrane, and detected using anti-KT3 antibody and chemiluminescence. 

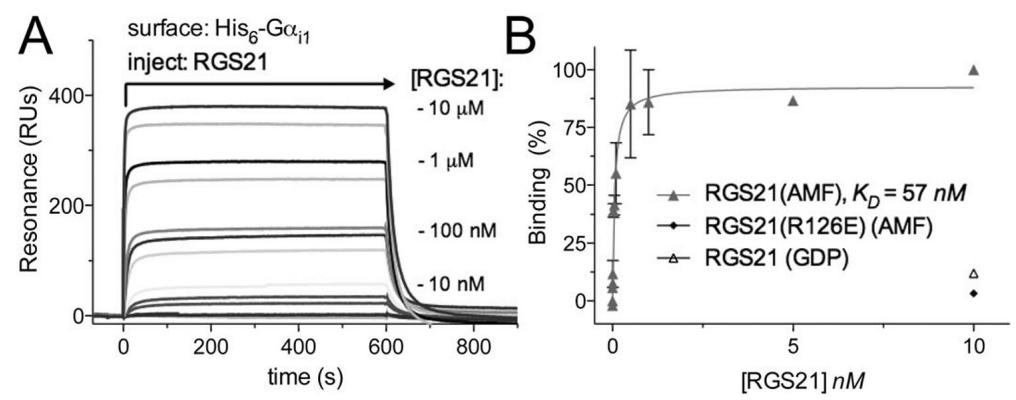

Fig. 5.

Recombinant regulator of G protein signaling-21 (RGS21) interacts with high affinity to $\mathrm{G} a_{\mathrm{i} 1}$. (A) $\mathrm{His}_{6}-\mathrm{G} a_{\mathrm{i} 1}$ was covalently immobilized on sensor surfaces for RGS21 binding analyses. Wildtype RGS21 or RGS21 (R126E) were separately injected at the indicated concentration at a flow rate of $20 \mu \mathrm{l} / \mathrm{min}$ for $600 \mathrm{~s}$ (start time $t=0 \mathrm{~s}$ ) over surfaces of $\mathrm{G} a_{\mathrm{i} 1}$ in the transition state (AMF) for GTP hydrolysis (i.e., GDP, $\mathrm{Mg}^{2+}$, and $\mathrm{AlF}_{4}^{-}$) or the inactive state (GDP-bound). (B) Resultant sensorgrams were used in equilibrium saturation binding analyses to derive dissociation constants. Error bars represent standard error of the mean (SEM). Wildtype RGS21 bound to wildtype $\mathrm{G} \alpha_{\mathrm{i} 1}$ (AMF) with an affinity of $57.0 \mathrm{nM}$ (95\% CI 28.3-85.7 nM). No appreciable binding was observed upon injection of wildtype RGS21 over immobilized $\mathrm{G} \alpha_{\mathrm{i} 1}$ (GDP) or RGS21(R126E) over immobilized $\mathrm{G} \alpha_{\mathrm{i} 1}$ (AMF). 

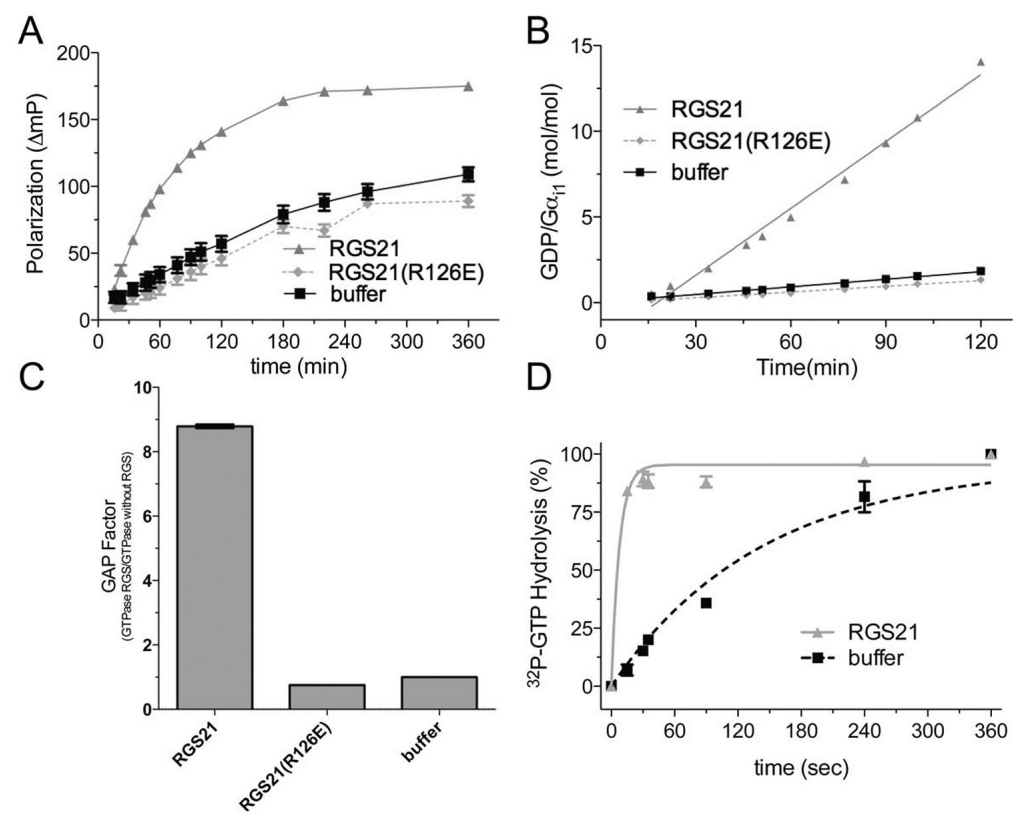

Fig. 6.

Recombinant regulator of G protein signaling-21 (RGS21) accelerates guanine diphosphate (GTP) hydrolysis of $\mathrm{G} \alpha_{\mathrm{i} 1}$. (A) $\mathrm{G} \alpha_{\mathrm{i} 1}(\mathrm{R} 178 \mathrm{M} / \mathrm{A} 326 \mathrm{~S}, 50 \mathrm{nM}$ ) was added to Transcreener GDP Assay Buffer with wildtype RGS21 (250 nM), RGS21(R126E; $250 \mathrm{nM})$, or buffer at $t$ $=0$. The addition of RGS21 increased the change in fluorescence polarization $(\Delta \mathrm{mP})$ over time compared to RGS21(R126E) or buffer alone. (B) $\Delta \mathrm{mP}$ was converted to GDP production using a standard curve for GDP detection in the presence of GTP. ${ }^{38}$ The steadystate rate of GDP production with RGS21, RGS21(R126E) or buffer was $0.13 \mathrm{~min}^{-1}(95 \%$ C.I $\left.0.12-0.14 \mathrm{~min}^{-1}\right), 0.011 \mathrm{~min}^{-1}$ (95\% C.I 0.010-0.012 $\mathrm{min}^{-1}$ ), and 0.0.15 (95\% C.I. 0.014-0.016 $\mathrm{min}^{-1}$ ), respectively. (C) GAP factors, defined as the ratio between steady-state GTPase rate in the presence of RGS protein and steady-state GTPase rate in the absence of RGS protein were computed. RGS21 has a GAP factor of 8.79 while RGS21(R126E) and buffer have GAP factors of 0.75 and 0.00 respectively. (D) A single round of GTP hydrolysis was measured wildtype $\mathrm{G} a_{\mathrm{i} 1}(100 \mathrm{nM})$ using ${ }^{32} \mathrm{P}-\mathrm{GTP}$. The intrinsic rate of GTP hydrolysis of $\mathrm{G} \alpha_{\mathrm{i} 1}$ was $0.0070 \mathrm{~min}^{-1}\left(95 \% \mathrm{CI} 0.0057-0.0083 \mathrm{~min}^{-1}\right)$. The addition of 50 $\mathrm{nM}$ of RGS21 increased the rate to $0.13 \mathrm{~min}^{-1}\left(95 \%\right.$ CI $\left.0.08-0.17 \mathrm{~min}^{-1}\right)$. 